\title{
A study on different factors impacting creative habits
}

\author{
Nahid Gharli Ronizi ${ }^{\mathbf{a}^{*}}$ and Zahra Gharli Ronizi ${ }^{\mathrm{b}}$
}

${ }^{a}$ M.Sc. of Commercial Management, Department of Management, University of Allame Tabatabaei, Tehran, Iran ${ }^{b}$ M.Sc. of Educational Management, University of Allame Tabatabaei, Tehran, Iran

\begin{tabular}{lll}
\hline A R T I C L E I N F O & A B S T R A C T \\
\cline { 3 - 3 } \cline { 3 - 3 } & & In this paper, we present an empirical study on employees of a private bank to find important \\
Received March 25, 2012 & factors influencing creative habits. The proposed study of this paper uses Pearson correlation \\
Received in revised format & test to detect any meaningful relationship between independent and dependent variables. The \\
17 October 2012 & results of the study have indicated that sense of being effective is number one priority followed \\
Accepted 17 October 2012 & by sense of competence and sense of being meaningful and sense of choice. We have also \\
Available online & performed an investigation between employees' personal characteristics and empowering \\
October 18 2012 & capabilities and the results of our survey have recommended that among different factors \\
\hline Keywords: & including age, gender, educational background and job experience, only age had important \\
Creative habits & effect on empowering employees. \\
Empowering &
\end{tabular}

(c) 2013 Growing Science Ltd. All rights reserved.

\section{Introduction}

During the past few years, there have been tremendous efforts on having more creative and innovative employees in organizations. Banking industry normally looks for those who could add values through creative and new ideas. During the past few years, there have been many studies associated with determining various factors influencing creative habits. Munteanu et al. (2010) investigate what effects have over students' creative potential and its components including divergent thinking, convergent thinking and creative attitudes being a frequent member of a creative group. They reported that group training developed substantially students' creativity potential, in general and by components. Bacanl et al. (2011) discussed creative thinking from quadruple thinking including critical, creative, caring and hopeful thinking ways. They also gave the etymology of the term, history of creativity thought, its dimensions and the supporting thinking ways. In addition, the creative thinking was compared with uncreative thinking and the quadruple thinking was shown in the association between creative thinking and other thinking ways.

* Corresponding author. Tel: +98912 3443139

E-mail addresses: N.Gharlironizi@bankmellat.ir (N. Gharli Ronizi)

(C) 2013 Growing Science Ltd. All rights reserved.

doi: $10.5267 / \mathrm{j} . \mathrm{msl} .2012 .10 .024$ 
According to Davis (2011), two interacting concepts, which impact both general and highly specialized types of creativity are either removing or minimizing barriers to creativity and fostering the growth of creative behaviors. Barriers are blocks, internal or external, which either inhibit creative thinking or prevent innovative insights from being accepted and implemented and most barriers result from learning. They normally originate with one's family, peers, community, or educational environment, or from others in the culture or business organizations. Creative attitudes are associated with a creative personality and creative behaviors include traits, which predispose one to think creatively and be creatively productive. The contrast between creative and uncreative people lies more in obstacles and uncreative attitudes than in changes in intelligence or thinking styles.

Simon (2006) proposed an empirical investigation on the concrete activities of project managers involved in creative projects, with a specific focus on "non-administrative" issues. They proposed an integrated synthesis of what creative project managers actually do based on four case studies in the video-game industry, multimedia, advertising and a circus. They identifies four sets of activities carefully coined to acknowledge the everyday involvement of project manager involved in creative projects and this is beyond analytical, cognitive, psychological, symbolic and discursive activities. They recommended that this project manager could act as a sense-maker, a web-weaver, a gamemaster and a flow-balancer. This empirical "picture" raises concerns on the technical and theoretical focus of research in project management where creativity is an utmost strategic subject.

Ansburg and Hill (2003), in another survey, discussed that creative and analytic thinkers differ in their use of attentional resources. They discussed that creativity involves linking ideas previously observed as unrelated. The creative thinker must take part in elements, which are associated with the current problem while recording seemingly irrelevant data, which may lead to insight. Therefore, creative thinkers must implement peripherally presented cues, effectively. Good analytic thinking need to be characterized by sustained directed attention because solutions to analytic problems need focus on the problem elements. Ansburg and Hill (2003) anticipated that creative thinkers could take advantage of incidentally presented cues, whereas analytic thinkers would not. They used a remote associates test (RAT) to measure creativity and deductive reasoning problems to measure analytic ability. Multiple regression analyses demonstrated that RAT scores forecasted ability to implement peripheral cues, whereas scores on the deductive task necessarily did not.

Yayin Wang (2012) explored whether extensive practice in reading or writing is associated with high creative performance. They reported that students who spent more time on reading/writing performed substantially better on the creativity test. This study specified that creativity scores, especially scores of elaboration were correlated with attitudes toward reading/writing, and the amount of time spent on reading/writing. Aizikovitsh-Udi and Amit (2011) investigated on issues for developing additional learning units within the traditional curriculum. They explored whether teaching specially designed learning unit would enhance the students' critical and or creativity thinking. It seems that the findings of this research could help composing new study programs and methods, which could be based on the connection between critical thinking, creative thinking and the study of mathematics.

The proposed study of this paper investigates the effects of different personal factors on creative habits among employees of Bank mellat in Iran.

\section{The proposed study}

In this paper, dependent variable is personal creative habits, which includes seven components as follows,

1. The use of lateral thinking: This helps go beyond technical and specialized limitations and find new assumptions out of existing boundaries. 
2. Use of luck intrusive: Paying attention to anything, which is around or working on a particular subject, which is about to happen.

3. Listen to the inner bays: Deep down on everything indeed.

4. Suspend judgment: This helps cancel all prejudgments and rely on other issues.

5. Steps compared: Any word or descriptive statement is normally transferred into one's mind in terms of descriptive pictures.

6. Tolerance of ambiguity: Creative people normally maintain higher levels of tolerance compared with others and do not jump into conclusion very too fast.

7. Banking ideas: Creative people use long-term strategies to equip their perceptions.

In addition, empowering is another independent variable, which could be described through the following features,

1. Sense of being effective: This helps people to accept the outcome of their achievements.

2. Sense of choice: This helps people feel of freedom in choosing their decisions.

3. Sense of competence: This helps people feel they are able to impact others.

4. Meaningful sense: This helps people feel better about their values.

The study uses the following formula to calculate the minimum number of sample size,

$$
n=\frac{N \times z_{\alpha / 2}^{2} \times p \times q}{\varepsilon^{2} \times(N-1)+z_{\alpha / 2}^{2} \times p \times q},
$$

where $N$ is the population size, $p=1-q$ represents the yes/no categories, $z_{\alpha / 2}$ is CDF of normal distribution and finally $\varepsilon$ is the error term. Since we have $p=0.5, z_{\alpha / 2}=1.96$ and $N=25068$, the number of sample size is calculated as $n=200$. The questionnaire includes the following questions,

\begin{tabular}{lll}
\hline Model & Component & Questions \\
\hline \multirow{4}{*}{ Empowering } & Sense of competence & $9-1-14-18-2$ \\
& Sense of choice & $10-15-19-3-4-$ \\
& Sense of being effective & $11-5-16-6$ \\
& Meaningful sense & $17-7-12-8-13$ \\
\hline \multirow{5}{*}{ Creative habits } & The use of lateral thinking & $31-20-32-21$ \\
& Use of luck intrusive & $33-22-$ \\
& Listen to the inner bays & $34-23$ \\
& Suspend judgment & $35-24-37-25$ \\
& Steps compared & $36-26$ \\
& Tolerance of ambiguity & $38-27$ \\
& Banking Ideas & $39-28-40-29-41-30$ \\
\hline
\end{tabular}

Note that in this paper, we have not been taken any actions associated with these independent variables and these items are measured based on an independent questionnaire. Cronbach alpha (Cronbach, 1951)has been calculated as 0.90 , which is well above the minimum acceptable level of 0.70 used in many other related works. We have used standard questionnaire for empowering. However, since there is no standard questionnaire associated with creative habits we have decided to 
design our own questionnaire. The following three hypotheses are associated with the first part of our survey,

1. There is a meaningful relationship between the feeling of empowering and employees' creative habits.

2. There is a meaningful relationship between the sense of choice and employees' creative habits.

3. There is a meaningful relationship between the sense of being effective and employees' creative habits.

The proposed study of this paper consists of three sections and the first section is associated with different empowering components while the second section is related to creative habits and the last part includes questions to learn more about population.

\subsection{Descriptive statistics}

We firs present some descriptive statistics in terms of gender, educational background, job position and job experiences. In this study, 205 people participated in our survey and 160 employees or $78 \%$ were male, 42 employees or $21 \%$ were female and three employees did not fill this part of our questionnaire. In terms of educational background, 183 employees or $89 \%$ of the participants maintained a bachelor degree of science, 19 employees representing $9 \%$ of the population of our survey had master degrees of science and the remaining $2 \%$ did not answer this question. In terms of age, 100 employees representing $49 \%$ of the participants were between 20 to 30 years of age, 94 people or $46 \%$ were between 30 to 40 years, 8 people representing one percent of the surveyed population were older than 40 and three people did not provide any response. Note that most participants in our survey were young people aging between 20 to 30 years of age. In our survey, 51 people or $25 \%$ were involved in management positions and the remaining were involved in regular job positions. The proposed study of this paper uses Pearson correlation test to detect any meaningful relationship between independent and dependent variables.

\section{The results}

In this section, we present details of our testing various hypotheses.

\subsection{The relationship between sense of competence and creative habits}

The first hypothesis is as follows,

$\mathrm{H}_{0}$ : There is not any meaningful relationship between sense of competence and creative habits.

$\mathrm{H}_{1}$ : There is a meaningful relationship between sense of competence and creative habits.

Spearman correlation test between these two components are calculated as 0.332 with p-value of 0.000 , which means we can reject the null hypothesis and conclude that there is a positive and meaningful relationship between sense of competence and creative habits when the level of significance is five percent.

\subsection{The relationship between sense of choice and creative habits}

The second hypothesis studies the relationship between sense of choice and creative habits and the result is as follows,

$\mathrm{H}_{0}$ : There is not any meaningful relationship between sense of choice and creative habits.

$\mathrm{H}_{1}$ : There is a meaningful relationship between sense of choice and creative habits. 
Spearman correlation test between these two components are calculated as 0.292 with p-value of 0.000 , which means we can reject the null hypothesis and conclude that there is a positive and meaningful relationship between sense of choice and creative habits when the level of significance is five percent.

\subsection{The relationship between sense of being effective and creative habits}

The second hypothesis studies the relationship between sense of being effective and creative habits and the result is as follows,

$\mathrm{H}_{0}$ : There is not any meaningful relationship between sense of being effective and creative habits.

$\mathrm{H}_{1}$ : There is a meaningful relationship between sense of being effective and creative habits.

Spearman correlation test between these two components are calculated as 0.366 with p-value of 0.000 , which means we can reject the null hypothesis and conclude that there is a positive and meaningful relationship between sense of being effective and creative habits when the level of significance is five percent.

\subsection{The relationship between sense of being meaningful and creative habits}

The second hypothesis studies the relationship between sense of being meaningful and creative habits and the result is as follows,

$\mathrm{H}_{0}$ : There is not any meaningful relationship between sense of being meaningful and creative habits.

$\mathrm{H}_{1}$ : There is a meaningful relationship between sense of being meaningful and creative habits.

Spearman correlation test between these two components are calculated as 0.266 with p-value of 0.000 , which means we can reject the null hypothesis and conclude that there is a positive and meaningful relationship between sense of being meaningful and creative habits when the level of significance is five percent.

\subsection{The effects of personal characteristics on empowering employees}

There are other findings associated with the proposed study of this paper in terms of relationship between gender, age, etc. and empowering.

\subsubsection{Gender and empowering}

The first hypothesis we consider in this section is the relationship between gender and empowering employees.

$\mathrm{H}_{0}$ : There is not any meaningful relationship between gender and empowering employees.

$\mathrm{H}_{1}$ : There is a meaningful relationship between gender and empowering employees.

Table 2 shows details of the implementation of t-student test between female and male participants.

\section{Table 2}

Statistical test between gender and empowering

\begin{tabular}{lllll}
\hline Gender & Mean of empowering & t-student & Degree of freedom & P-value \\
\hline Male & 3.69 & 0.169 & 200 & 0.866 \\
Female & 3.70 & & & \\
\hline
\end{tabular}


As we can observe from the results of t-student, there is no meaningful relationship between these two variables and we cannot reject the null hypothesis. We can conclude that gender has no impact on empowering employees.

\subsubsection{Age and empowering}

The second hypothesis we consider in this section is the relationship between age and empowering employees.

$\mathrm{H}_{0}$ : There is not any meaningful relationship between age and empowering employees.

$\mathrm{H}_{1}$ : There is a meaningful relationship between age and empowering employees.

Table 3 shows details of the implementation of t-student test between participants' aging characteristics.

Table 3

Statistical test between age and empowering

\begin{tabular}{lllll}
\hline Age(Year) & Mean of empowering & t-student & Degree of freedom & P-value \\
\hline$<30$ & 3.62 & -2.213 & 200 & 0.028 \\
$\geq 30$ & 3.76 & & & \\
\hline
\end{tabular}

As we can observe from the results of t-student, there is statistically meaningful relationship between these two variables and we can simply reject the null hypothesis and conclude that age impacts on empowering employees.

\subsubsection{Educational background and empowering}

The third hypothesis we consider in this section is the relationship between educational background and empowering employees.

$\mathrm{H}_{0}$ : There is not any meaningful relationship between educational background and empowering employees.

$\mathrm{H}_{1}$ : There is a meaningful relationship between educational background and empowering employees.

Table 4 shows details of the implementation of t-student test between educational backgrounds of participants.

\section{Table 4}

Statistical test between educational background and empowering

\begin{tabular}{lllll}
\hline Education & Mean of empowering & t-student & Degree of freedom & P-value \\
\hline Bachelor & 3.71 & 1.489 & 200 & 0.138 \\
Master & 3.55 & & & \\
\hline
\end{tabular}

As we can observe from the results of t-student, there is no meaningful relationship between these two variables and we cannot reject the null hypothesis. We can conclude that educational background has no impact on empowering employees.

\subsubsection{Job position and empowering}

The fourth hypothesis we consider in this section is the relationship between job position and empowering employees. 
$\mathrm{H}_{0}$ : There is not any meaningful relationship between job position and empowering employees.

$\mathrm{H}_{1}$ : There is a meaningful relationship between job position and empowering employees.

Table 5 shows details of the implementation of t-student test between employees with management position and non-management positions.

\section{Table 5}

Statistical test between job position and empowering

\begin{tabular}{lllll}
\hline Education & Mean of empowering & t-student & Degree of freedom & P-value \\
\hline Management & 3.68 & -0.323 & 199 & 0.743 \\
Others & 3.70 & & & \\
\hline
\end{tabular}

As we can observe from the results of t-student, there is no meaningful relationship between these two variables and we cannot reject the null hypothesis. We can conclude that job position has no impact on empowering employees.

\subsubsection{Job position and empowering}

The fourth hypothesis we consider in this section is the relationship between job position and empowering employees.

$\mathrm{H}_{0}$ : There is not any meaningful relationship between job position and empowering employees.

$\mathrm{H}_{1}$ : There is a meaningful relationship between job position and empowering employees.

Table 6 shows details of the implementation of t-student test between employees's job experiences.

\section{Table 5}

Statistical test between job experince and empowering

\begin{tabular}{lllll}
\hline Education & Mean of empowering & t-student & Degree of freedom & P-value \\
\hline$<10$ & 3.66 & -1.478 & 200 & 0.141 \\
$\geq 10$ & 3.76 & & & \\
\hline
\end{tabular}

As we can observe from the results of t-student, there is no meaningful relationship between these two variables and we cannot reject the null hypothesis. We can conclude that job experience has no impact on empowering employees.

\subsection{Ranking empowering features}

The final step is to rank different items investigated using Freedman test. Table 6 shows details of our finding,

Table 6

Details of results of freedman test

\begin{tabular}{lll}
\hline Title & Freedman & Rank \\
\hline Sense of being effective & 3.07 & First \\
Sense of competence & 2.70 & Second \\
Sense of being meaningful & 2.32 & third \\
Sense of choice & 1.91 & Forth \\
\hline
\end{tabular}


The results of Freedman yields 96.873 with three degree of freedom and P-value of 0.000 , which confirms the test and the results indicate that sense of being effective is number one priority followed by sense of competence and sense of being meaningful and sense of choice.

\section{Conclusion}

In this paper, we have presented and empirical study on employees of a private bank in Iran to find important factors on creative habits. The results of the study have indicated that sense of being effective was number one priority followed by sense of competence and sense of being meaningful and sense of choice. We have also performed an investigation between employees' personal characteristics and empowering capabilities and the results of our survey have recommended that among different factors including age, gender, educational background and job experience, only age had important effect on empowering employees.

\section{Acknowledgment}

This paper was financially assisted by Bank Mellet, the authors also would like to thank the anonymous referees for their constructive comments on earlier version of this paper.

\section{References}

Aizikovitsh-Udi, E., \& Amit, M. (2011). Developing the skills of critical and creative thinking by probability teaching. Procedia - Social and Behavioral Sciences, 1087-1091.

Ansburg, P.I., \& Hill, K. (2003). Creative and analytic thinkers differ in their use of attentional resources. Personality and Individual Differences, 34(7), 1141-1152.

Bacanl1, H., Dombayc1, M.A., Demir, M., \& Tarhan, S. (2011). Quadruple Thinking: Creative Thinking. Procedia - Social and Behavioral Sciences, 12, 536-544.

Cronbach, L. J. (1951). Coefficient alpha and the internal structure of tests. Psychometrika, 16(3), 297-334.

Davis, G.A. (2011). Barriers to Creativity and Creative Attitudes. Encyclopedia of Creativity, $2^{\text {nd }}$, 115-121.

Likert, R. (1932). A Technique for the Measurement of Attitudes. Archives of Psychology, 140, 1-55.

Munteanu, A., Costea, I., \& Jinaru, A. (2010). Developing links in creative group training at university level. Procedia - Social and Behavioral Sciences, 2(2), 1825-1829.

Simon, L. (2006). Managing creative projects: An empirical synthesis of activities. International Journal of Project Management, 24(2), 116-126.

Yayin Wang, A. (2012). Exploring the relationship of creative thinking to reading and writing. Thinking Skills and Creativity, 7(1), 38-47 